\title{
Removal of Heavy Metal from Drinking Water Supplies through the Ion Exchange Membrane-A Review
}

\author{
Anjum Praveen ${ }^{1}$, Rajesh Kumar ${ }^{2}$, Pratima ${ }^{3}$ and Rajat Kumar ${ }^{4}$ \\ ${ }^{I}$ Reseach Scholar of Singhania University, Jhunjhunu Rajasthan, India \\ ${ }^{2}$ Department of Chemical Engg. HBTI Kanpur, India \\ ${ }^{3,4}$ Department of Chemistry DAV-PG College Kanpur, India
}

\begin{abstract}
During the last 50 years, ion exchange membranes have evolved from a laboratory tool to industrial products with significant technical and commercial impact. Today ion exchange membranes are receiving considerable attention and are successfully applied for desalination of sea and brackish water and for treating industrial effluents. They are efficient tools for the concentration or separation of food and pharmaceutical products containing ionic species as well as the manufacture of basic chemical products. The evolvement of an ion exchange membrane not only makes the process cleaner and more energy-efficient but also recovers useful effluents that are now going to wastes, and thus makes the development of society sustainable. Therefore, the intention of this review is to give a brief summary of the different preparation and characteristics of ion exchange membrane as well as their potential applications. The most relevant literatures in the field are surveyed and some elucidating case studies are discussed, also accounting for the results of some research programs carried out in the author's laboratory.
\end{abstract}

Keywords: Ion exchange membranes; Amphoteric ion exchange membrane; Bipolar membrane; Mosaic ion exchange membranes; Hybrid ion exchange membrane; Electrodialysis.

\section{Introduction}

The rapid increases in the human population and the rapid pace of Industrialization in India have created problems of waste disposal with the recent past. In general the domestic wastes and the industrial effluents are being by and large, indiscriminately discharged in the nearby fresh water resources without any treatment. Therefore, a rapid Degradation of water quality has been envisaged in the past years and Concrete steps are required to be taken immediately to abate water Pollution. Keeping the above aspect in view to cope with the problems the Present investigation has been undertaken. In the present study our Effort is to evaluate the feasibility of generating the condition suitable for bioremediation of induction wastewater in industrial areas of Kanpur district. Mercury is a significant environmental toxin that can be deadly to humans.

\subsection{Fresh Water Crisis}

Water is, literally, the source of life on earth. About 70 percent of the earth is water, but only one

Percent is accessible surface freshwater. The one percent surface fresh water is regularly renewed by rainfall and other means and thus available on a sustainable basis and easily considered accessible for human use. Water is the biggest crisis facing the world today. In India the crisis in terms spread and severity affects one in three people. As per an estimate in 2000 , there were 7,800 cubic meters of fresh water available per person annually. It will be 5,100 cubic meters $(51,00,000$ liters) by 2025 . Even this amount is sufficient for human needs, if it were properly distributed. But, equitable distribution is not possible India, which has 16 percent of world's population, 2.45 percent of world's land area and 4 percent of the world's water resources, has already faced with grave drinking water crisis. Water is the single largest problem facing India today. Years of rapid population growth and increasing water consumption for agriculture, industry and municipalities and other areas have strained Indian fresh water resources. In many parts of our country chronic water shortages, loss of arable land, destruction of natural habitats, degradation of environment, and widespread pollution undermine public health and threaten economic and social progress. By 2050 more than 50 percent of population is expected to shift to the cities and the drinking water scarcity will be acute. In the developed world, for example, the United Kingdom must spend close to $\$ 60$ billion building wastewater treatment plants over the next decade to meet the new European water quality standards. The World Bank has estimated that over the next decade between US \$ 600 to 800 billion will be required to meet the total demand for fresh water, including that for sanitation, irrigation and power generation. A water short world is inherently unstable world. Now the world needs another revolution, i.e., a Blue Revolution for conservation and proper maintenance of freshwater.

One in eight people in the world today lack access to clean drinking water. A child dies every 15 seconds from a lack of clean water. One in four children who die before age five worldwide, die of a water related disease. Most people without access to clean water live right above it. In many cases the only thing 
preventing access to clean water is money1. Access to clean water is the foundation of development. Food, health, hygiene, habitat, education, employability, productivity are all dependent upon access to water. Without clean water, none of these is possible and poverty is inevitable. Majority of these people are in the developing world.

Over the years, India has made improvements to both the availability and quality of municipal drinking water systems. However the exponentially growing population has stressed existing water systems and resources. The pressures of urbanization have stretched government solutions. Rural areas are still left out. Many water sources are contaminated with both bio and chemical pollutants, and over $21 \%$ of the country's diseases are water-related.

The Department for International Development (DFID) leads the UK Government's fight against global poverty. To take this agenda forward DFID is establishing a research programme to help engage with those new and emerging technologies with the potential to impact on poverty in a way that enables developing countries to take advantage of what they have to offer. Through this research, Technology and Action for Rural Advancement (TARA) seeks to identify key challenges and barriers that may reduce the impact of technologies such as Nanotechnologies for providing clean drinking water reaching the underprivileged in developing countries, it's possible environmental implications and remedial measures.

Only $2.53 \%$ of earth's water is fresh, and some two-thirds of that is locked up in glaciers and permanent snow cover. Nearly one billion people - one in eight persons in the world - lack access to safe water supply. Over 3.5 million people die each year from water-related disease; $84 \%$ are children. $98 \%$ occur in the developing world. Sixty five million people are at risk of arsenic poisoning in the Bangladesh, India and Nepal area. The water and sanitation crisis claims more lives through disease than any war claims through guns [2].

Indian government surveys reveal that only $30 \%$ of the rural population had access to safe drinking (tap) water in the country. $55 \%$ depend on tube well or hand pumps to meet their drinking water requirement. $15 \%$ of rural populations were still looking for a dependable source of water. In urban areas, $74 \%$ depend on tap water and $18 \%$ on tube well/hand pump [2].

Altogether the cost of environmental damage is estimated to be $\$ 9.7$ billion per year, of the most vital is the health impacts of water pollution accounting for $59 \%$ of the total value of degradation. Waterborne diseases (the consequence of a combination of lack of clean water supply and inadequate sanitation) cost the Indian economy 73 million working days a year. Water quality is a major problem in both ground and surface water. Although in their upper reaches most rivers are of good quality, the middle and lower reaches of almost all rivers face major degradation. Some of the key pollutants and their sources are summarized below.

Microbial contamination (faecal) mainly arises from inadequately treated or untreated sewage. Lack of sanitation and sewage treatment facilities is the main cause for this.

- Heavy metal contaminated waste water from industrial activities such as electroplating, textile dyeing; tanneries etc reach the surface or ground water sources if it's inadequately treated. In addition leaching from solid waste dumps (e.g. fly ash ponds, sludge from above industries) also contributes towards heavy metal accumulation.

- High salinity arises from decreasing groundwater levels and seawater intrusion. This is also aggravated by agricultural run offs, which are rich in salts.

- Arsenic, fluoride, nitrate, nickel and organic waste phenol contaminants enter groundwater aquifers from their presence in the sediments of the region. This has been further aggravated by excessive groundwater withdrawals.

- Micropollutants include pesticides, endocrine disrupting substances, and surfactants. These arise from agricultural run offs and from sewage.

Water that does not meet drinking water standards should be treated to ensure that the health of the consumer or community is not compromised through exposure to toxic pollutants. Water supply systems in urban India are mainly centralized and managed by municipal bodies. Certain levels of treatment and purification occur at source before distribution via a piped network. Chlorination is the most common measure. Rural India depends on varied localized sources to meet its water needs. Traditionally households boil water before consumption. Urban markets today are flooded with household water purifiers catering to the middle and upper classes. The technologies used vary from reverse osmosis to UV purification to ionization, iodine filters, etc.

Polluted water is often treated by conventional or pressure-driven membrane processes to make it comply with drinking water standards. Conventional water treatment process consists of several stages. These include pre-treatment, coagulation, flocculation, sedimentation, disinfection, aeration, and filtration. The pretreatment stage removes suspended solids. Coagulation and flocculation are carried out to precipitate dissolved impurities through sedimentation. The water is then filtered to remove any suspended particles. One of the 
disadvantages of the conventional water treatment method is that it cannot remove dissolved salts and some soluble inorganic and organic substances.

The DFID Research Strategy 2008 - 2013 recognises a key role for research to help anticipate and respond to future trends with respect to new and emerging cutting edge technologies that could have a real relevance to the needs of poor people. The Research Strategy also recognises that the challenge for DFID lies not in the development or commercial application of these technologies, but in translational research to support the longer term development agenda. Research is needed into the most effective, safe and affordable approaches to applying these new technologies in developing country situations and to ensuring the benefits are derived by the poorest. Purifying drinking water is one of the strategic areas for the research with a special focus on nanotechnology. TARA has undertaken this research to identify the key challenges and barriers that may be reducing the impact of these technologies on the lives of poor people and help to identify some of the key technologies that could form the basis of further work.

\subsection{Major uses and sources in drinking-water}

The primary source of nickel in drinking-water is leaching from metals in contact with drinking-water, such as pipes and fittings. However, nickel may also be present in some ground waters as a consequence of dissolution from nickel ore-bearing rocks.

Nickel is used principally in its metallic form combined with other metals and nonmetals as alloys [1]. Nickel alloys are characterized by their hardness, strength, and resistance to corrosion and heat. Nickel is used mainly in the production of stainless steels, non-ferrous alloys, and super alloys. Other uses of nickel and nickel salts are in electroplating, as catalysts, in nickel-cadmium batteries, in coins, in welding products, and in certain pigments and electronic products (IARC, 1990). It is estimated that $8 \%$ of nickel is used for household appliances (IPCS, 1991). Nickel is also incorporated in some food supplements, which can contain several micrograms of nickel per tablet (EU, 2004).

\subsection{Environmental pollution}

Environmental pollution is an emerging threat and of great concern in today's context pertaining to its effect on the ecosystem. Water pollution is one of the greatest concerns now a day. In recent years, considerable attention has been paid to industrial wastes discharged to land and surface water. Industrial effluents often contain various toxic metals, harmful dissolved gases, and several organic and inorganic compounds. These may accumulate in soil in excessive quantities in long-term use, ultimately physiologically adverse effects on crop productivity.

The worldwide rise in population and the industrialization during the last few decades have resulted in ecological unbalance and degradation of the natural resources. One of the most essential natural resources, which have been the worst victim of population explosion and growing industrialization, is water. Huge quantity of wastewater generated from human settlement and industrial Sectors accompany the disposal system either as municipal wastewater or industrial wastewater. This wastewater is enriched with varied pollutants and harmful both for human being and the aquatic flora and fauna, finds its way out into the nearly flowing or stationary water bodies and thus makes natural sources of water seriously contaminated.

It has been estimated that over 5 million chemical substances produced by industries have been identified and about 12000 of these are marketed which amount to around half of the total production. Due to discharge of toxic effluents long-term consequence of exposure can cause

Cancer, delayed nervous damage, malformation in urban children, mutagenic changes, neurological disorders etc. Various acid manufacturing industries discharge acidic effluent, which not only make the land infertile. But make the water of the river acidic also. The high acidity causes stomach diseases and skin ailments in human beings.

Nickel is a lustrous white, hard, ferromagnetic metal. It occurs naturally in five isotopic forms: 58 $(67.8 \%), 60(26.2 \%), 61(1.2 \%), 62(3.7 \%)$, and $64(1.2 \%)$. Nickel usually has two valence electrons, but oxidation states of $+1,+3$, or +4 may also exist. Metallic nickel is not affected by water but is slowly attacked by dilute hydrochloric or sulfuric acid and is readily attacked by nitric acid. Fused alkali hydroxides do not attack nickel. Several nickel salts, such as the acetate, chloride, nitrate, and sulfate, are soluble in water, whereas carbonates and hydroxides are far less soluble and sulfides, disulfides, subsulfides, and oxides are practically insoluble in water. Alloys of nickel containing more than $13 \%$ chromium are to a high degree protected from corrosion in many media by the presence of a surface film consisting mainly of chromium oxide (Morgan \& Flint, 1989; Haudrechy et al., 1994). 


\section{Environmental Levels And Human Exposure}

\subsection{Air}

Nickel concentrations in remote areas are in the range of $1-3 \mathrm{ng} / \mathrm{m} 3$, whereas concentrations in rural and urban air range from 5 to $35 \mathrm{ng} / \mathrm{m} 3$. It has been estimated that non-occupational exposure via inhalation is $0.2-1.0 \mu \mathrm{g} /$ day in urban areas and $0.1-0.4 \mu \mathrm{g} /$ day in rural areas (Bennett, 1984). The mainstream smoke of one cigarette contains about $0.04-0.58 \mu \mathrm{g}$ of nickel (IARC, 1990).

\subsection{Water}

Nickel concentrations in groundwater depend on the soil use, $\mathrm{pH}$, and depth of sampling. The average concentration in groundwater in the Netherlands ranges from $7.9 \mu \mathrm{g} /$ litre (urban areas) to $16.6 \mu \mathrm{g} /$ litre (rural areas). Acid rain increases the mobility of nickel in the soil and thus might increase nickel concentrations in groundwater (IPCS, 1991). In groundwater with a pH below 6.2, nickel concentrations up to $980 \mu \mathrm{g} /$ litre have been measured (RIVM, 1994).

In Canada, the median nickel level in drinking-water supplies was below the detection limit of $2 \mu \mathrm{g} / \mathrm{litre}$; the maximum level observed was $69 \mu \mathrm{g} /$ litre (Méranger et al., 1981). In drinking-water in the USA, $90 \%$ of all samples $(n=2503)$ contained $\leq 10 \mu \mathrm{g} /$ litre, and $97 \%$ had nickel concentrations of $\leq 20 \mu \mathrm{g} /$ litre (ATSDR, 1996).

In Europe, reported nickel concentrations in drinking-water were generally below $10 \mu \mathrm{g} /$ litre (IPCS, 1991). Nickel levels below $1 \mu \mathrm{g} /$ litre have been reported from Denmark and Finland (Punsar et al., 1975; Gammelgaard \& Andersen, 1985). Average dissolved nickel concentrations in surface water in the rivers Rhine and Meuse are below $7 \mu \mathrm{g} /$ litre (RIWA, 1994).

Increased nickel concentrations in groundwater and municipal tap water $(100-2500 \mu \mathrm{g} / \mathrm{litre})$ in polluted areas and areas in which natural nickel was mobilized have been reported (McNeely et al., 1972; Hopfer et al., 1989). Water left standing overnight in plumbing fittings plated with chromium on a base of nickel contained a nickel concentration of $490 \mu \mathrm{g} /$ litre (Andersen et al., 1983).

Certain stainless steel well materials were identified as the source of increased nickel concentrations in groundwater wells in Arizona, USA. Mean nickel levels were 8-395 $\mu \mathrm{g} /$ litre; in some cases, nickel levels were in the range $1-5 \mathrm{mg} / \mathrm{litre}$ (Oakley \& Korte, 1996).

Leaching of nickel from chromium-nickel stainless steel pipe work into drinking water diminished after a few weeks; as chromium was rarely found at any time in the water, this indicates that the leakage of nickel is not of corrosive origin, but rather attributable to passive leaching of nickel ions from the surface of the pipes (Schwenk, 1992). Concentrations of nickel leaching from new stainless steel pipes used for drinking-water were up to $6 \mu \mathrm{g} /$ litre (Nickel Development Institute, personal communication, 2004). This maximum concentration can be increased when the pipes are assembled with tinned copper and gunmetal fittings. Fittings such as taps, which are chromium-plated, release much higher concentrations, but these decrease significantly with time (EU, 2004).

Nickel concentrations in bottled mineral water will depend on the source and any treatment applied. Levels of nickel in a selection of bottled mineral waters were below the detection limit of $25 \mu \mathrm{g} /$ litre (Allen et al., 1989).

Arsenic is common in areas where there are metallic ore mining operations. Arsenic has also been used as a pesticide, a wood preservative, and in paints, dyes, metals, drugs, soaps, and semi-conductors [2]. Generally, naturally occurring arsenic has not been identified as a major concern in Rhode Island's groundwater as it has in other New England states such as New Hampshire and Maine. Arsenic has been widely used throughout the United States and the Northeast as a pesticide on fruit orchards and on some other crops. Though use of arsenic as a pesticide has been widely discontinued, it is possible that a buildup of arsenic in the soil has occurred over the years. There are other industrial sites that historically or presently could result in release of arsenic to the environment including: manufacturing of metals and alloys, pharmaceuticals, pesticides, and chemicals, and petroleum refining and waste incineration.

\subsection{Homogeneous ion exchange membranes}

\section{Various Options For Removal Of Heavy Metal}

\subsection{Inorganic-organic (hybrid) ion exchange membranes}

3.3 Bipolar ion exchange membranes

3.4Amphoteric ion exchange membranes

3.5 Mosaic ion exchange membranes

\subsection{Novel processes based on ion exchange membranes}

3.1 Homogeneous ion exchange membranes

Tongwen Xu [3]. To prepare homogeneous ion exchange membranes, various approaches are available to introduce ionic groups. These approaches can be classified into three categories based on the starting materials. 
(a) Starting with a monomer containing a moiety that either is or can be made anionic or cationic exchange groups, which can be copolymerized with non-functionalized monomer to eventually form an ion exchange membrane.

(b) Starting with polymer film, which can be modified by introducing ionic characters either directly by grafting of a functional monomer or indirectly by grafting nonfunctional monomer followed by functionalization reaction.

(c) Start with polymer or polymer blends by introducing anionic or cationic moieties, followed by the dissolving of polymer and casting it into a film. If the membrane is prepared from monomer, styrene and divinylbenzene are most commonly utilized neutral starting material for a traditional hydrocarbon type ion exchangemembrane for industrial uses, from which a strongly basic anion exchange membrane is usually prepared by two steps, chloromethylation and quaternary amination and the cation exchange membrane prepared by sulfonation. There exist numerous references in the literature for homogeneous ion exchange membrane preparation using such method.

A great deal work has been dedicated to prepare ion exchange membranes from polymer film. Generally, these polymers are insoluble to any solvents, such as polymer films of hydrocarbon PE and PP or fluorocarbon origin (PTFE, FEP, PFA, ETFE and PVDF). In such route, two functional acidic groups were mainly identified as fixed ionic groups that confer the membrane its cation character, namely carboxylic (weakly acidic) and sulfonic acid (strongly acidic) groups. The former can be prepared either by direct grafting of acrylic monomers like acrylic, methacrylic acids and their mixtures with acrylonitrile and vinylacetate or by grafting of epoxy acrylate monomers, such as glycidyl acrylate or glycidyl methacrylate onto polymer films followed by the conversion of the epoxy group into carboxylic group, such as iminodiacetate groups which were obtained by post-grafting ring opening reaction. Strongly acidic membranes are commonly prepared by grafting of styrene onto polymer films and the resulted graft copolymer films are subsequently sulfonated.

Also, significant efforts have been made to prepared anion exchange membranes from analogous polymer films. The common used method is the same as the second one of cation exchange membrane: grafting vinyl monomers, such as styrene onto polymer films followed by subsequent chemical modifications, such as chloromethylation-amination instead of sulfonation $[4,5]$. An alternative way is to graft copolymerization of vinyl monomers, such as 4-vinylpyridine, 2 vinylpyridine and vinylbenzylchloride onto various polymer films using various grafting technologies, such asUV-induce plasma and irradiation methods. Anion exchange functional groups can be either strongly basic, such as tertiary ammonium or weakly basic, such as primary, secondary or tertiary amine groups.

Scheme 1 presents a reaction route for preparing such anion exchangemembrane.
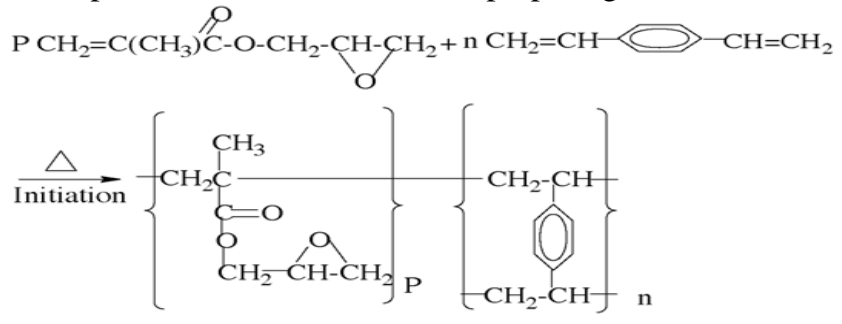

Step 1

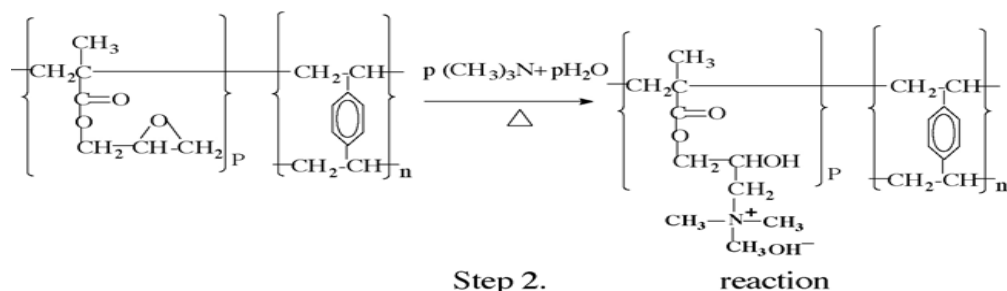

Scheme 1. Anion exchange membrane preparation by ring opening reaction of epoxy group instead of chloromethylationwith chloromethyl methyl ether. Step 1, copolymerization reaction. Step 2, quaternary amination reaction.

\subsection{Inorganic-organic (hybrid) ion exchange membranes}

Inorganic-organic composite materials are increasingly important due to their extraordinary properties within a single molecular composite, which arise from the synergism between the properties of the components. These materials have gained much interest owing to the remarkable change in properties, such as mechanical, thermal, electrical and magnetic compared to pure organic polymers or inorganic materials. In these materials, 
organic materials offer structural flexibility, convenient processing, tunable electronic properties, photoconductivity, efficient luminescence and the potential for semiconducting and even metallic behavior. Inorganic compounds provide the potential for high carrier mobilities, band gap tunability, a range of magnetic and dielectric properties and thermal and mechanical stability. In addition to combining distinct characteristics, new or enhanced phenomena can also arise as a result of the interface between the organic and inorganic components.

\subsection{Bipolar ion exchange membranes}

A bipolar membrane (BPM) is a kind of composition membrane that at least consists of a layered ionexchange structure composed of a cation selective layer (with negative fixed charges) and an anion selective layer (with positive fixed charges). Just the same as the discovery of semiconductor $\mathrm{N}-\mathrm{P}$ junctions brings about the invention of many new semiconductor instruments, this composition of anionic and cationic exchange layer brings about many novelties [14-19], such as separation of mono-and divalent ions, anti-deposition, antifouling, water dissociation, etc. Particularly, electrodialytic water splitting employing bipolar membranes to produce acids and bases from the corresponding salts as shown in Fig. 1 has become a new growth point in electrodialysis industries, and great potentialities exist in industries and daily life, such as chemical production and separation, biochemical engineering, environmental conservation, etc. [20-23]. The involvement of a BPM in these fields can significantly change the features of conventional processes and eliminate potential contamination to the environment [24].

Electrodialytic water dissociation with a bipolar membrane is a very energy-efficient way to produce acids and bases from the corresponding salts, because the set-up can consists of hundreds of cell units stacked between two electrodes like a conventional electrodialysis. However, there are still severe problems, such as the instability of a bipolar membrane at high over limiting current density conditions [24]. Therefore, the most crucial aspect of these applications is the bipolar membrane itself. For preparing such membranes, various methods has been initiated, such as preparing directly from commercial cation and anion exchange membranes by adhering with heat and pressure or with an adhesive paste [25], preparing by casting a cation exchange polyelectrolyte solution (or an anion exchange polyelectrolyte solution) on a commercial anion exchange membrane (or on a cation exchange membrane) respectively [26,27], or preparing from the same base membrane by simultaneous functionalizing at the two membrane sides [28-30] or selectively functionalizing on one side to give cation selectivity and on the other side to give anion selectivity, etc. [31].

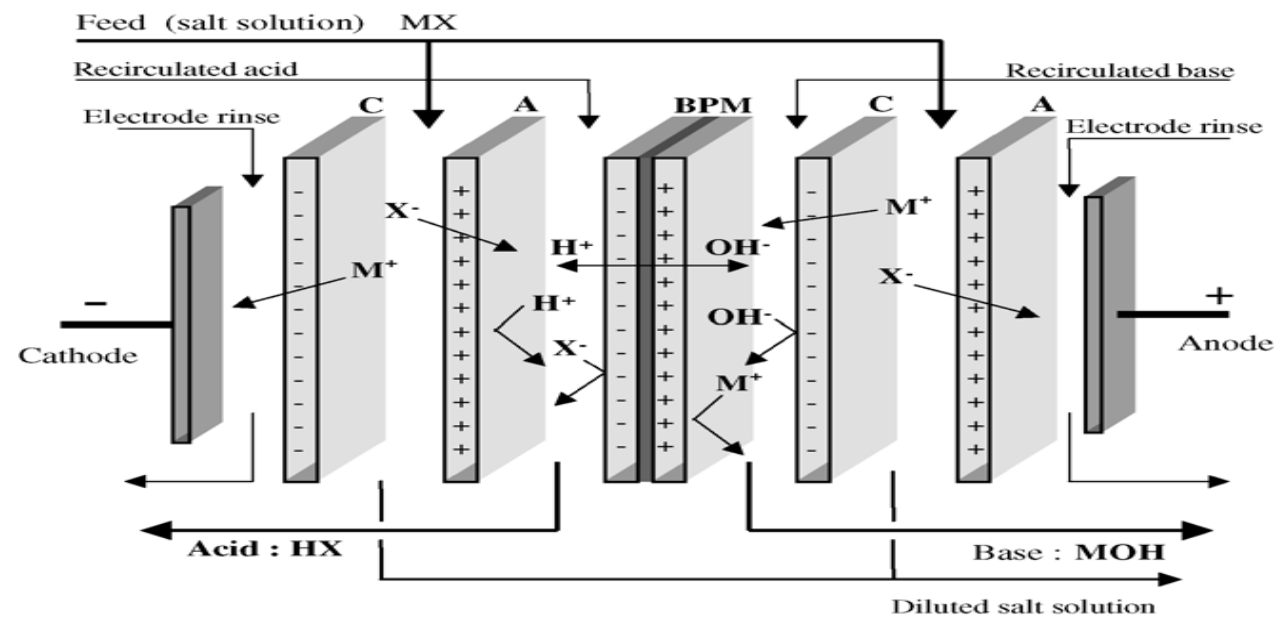

Fig. 1. Electrodialysis with bipolar membranes for the conversion of a salt MX into its respective acid HX and base $\mathrm{MOH}$, taken from Ref. [32].

The two ion exchange layers in a bipolar membrane allow for the selective transport of the water dissociation products_-protons and hydroxyl ions and block co-ions in the electrolyte. To facilitate the water splitting effect, a bipolar membrane also includes a contact region, also referred to the interfacial layer, where the desired water dissociation reaction occurs. The charged groups and structure of this region are of great significance for water dissociation and thus generally are modified elaborately to improve the bipolar membrane's performance. Now, it is well concluded that materials with the best catalytic activity are sufficient amounts of weak acids (and the corresponding bases), such as amino groups, pyridine, carboxylic acid, phenolic and phosphoric acid group [33-36] as well as heavy metal ion complexes, such as ruthenium trichloride, chromic nitrate, indium sulfate, hydrated zirconium oxide, etc. [37-40]. The catalytic mechanism is underlined 
by chemical reaction model of water dissociation, that is, the water splitting could be considered as some type of proton-transfer reaction between water molecules and the functional groups or chemicals [35, 41]:

$\begin{array}{ll}\mathrm{B}+\mathrm{H}_{2} \mathrm{O}_{-} \mathrm{BH}+\cdots \cdot \mathrm{OH}- & \mathrm{BH}++\mathrm{OH}- \\ \mathrm{BH}++\mathrm{H} 2 \mathrm{O}{ }_{-} \mathrm{B} \cdot \cdot \mathrm{H} 3 \mathrm{O}++_{-} \mathrm{B}+\mathrm{H} 3 \mathrm{O} & 2\end{array}$

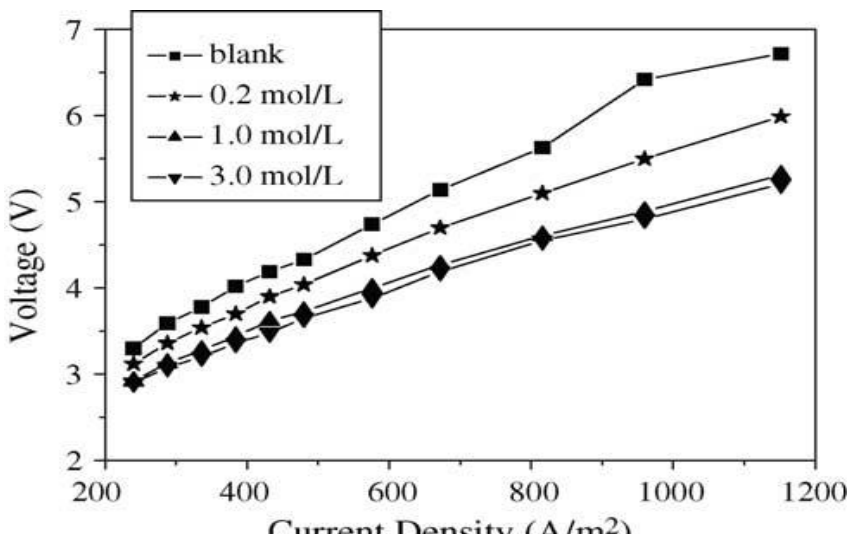

Current Density $\left(\mathrm{A} / \mathrm{m}^{2}\right)$

Fig. 2. The $I-V$ curves of bipolar membranes of which the anion exchange membranes have been immersed in different concentration solutions of PEG 2000.

$$
\begin{gathered}
\stackrel{\text { or }}{\mathrm{A}-}+\mathrm{H} 2 \mathrm{O}_{-} \mathrm{AH} \cdot \cdot \mathrm{HO}_{-}-\mathrm{AH}+\mathrm{OH}- \\
\mathrm{AH}+\mathrm{H} 2 \mathrm{O}_{-} \mathrm{A}-\cdots \cdot \mathrm{H} 3 \mathrm{O}+{ }_{-} \mathrm{A}-+\mathrm{H} 3 \mathrm{O}
\end{gathered}
$$

Where $\mathrm{BH}+$ andA- refer to the catalytic centers. The catalytic sites provide an alternative path with low effective activation energy for water splitting into hydrogen and hydroxyl ions. In order to further elucidate the relationship between the water splitting effect and the chemical composition of the middle layer and to find the varieties in catalyst, current jobs in the author's laboratory are concentrating on using macromolecules, such as polyethylene glycol (PEG) [42],

bio-macromolecule bovine serum albumin (BSA) containing both carboxylic and amino groups [43], starburst dendrite's [44], as well as polyvinyl alcohol (PVA) [45] as the interfacial layer to catalyze water dissociation in a bipolar membrane. We have surprisingly found that PEG has greatly improved performance of bipolar membranes from the viewpoint of the $I-V$ curves as shown in Figs. 2 and 3. Further, This catalytic effect not increases with the adsorbed concentration (Fig. 2) but increase with the molecular weight as well (Fig. 3). But for the same material, such as PVA, which has more hydroxyl groups than PEG, the function is much Fig. 6. But for the same material, such as PVA, which has more hydroxyl groups than PEG, the function is much different.

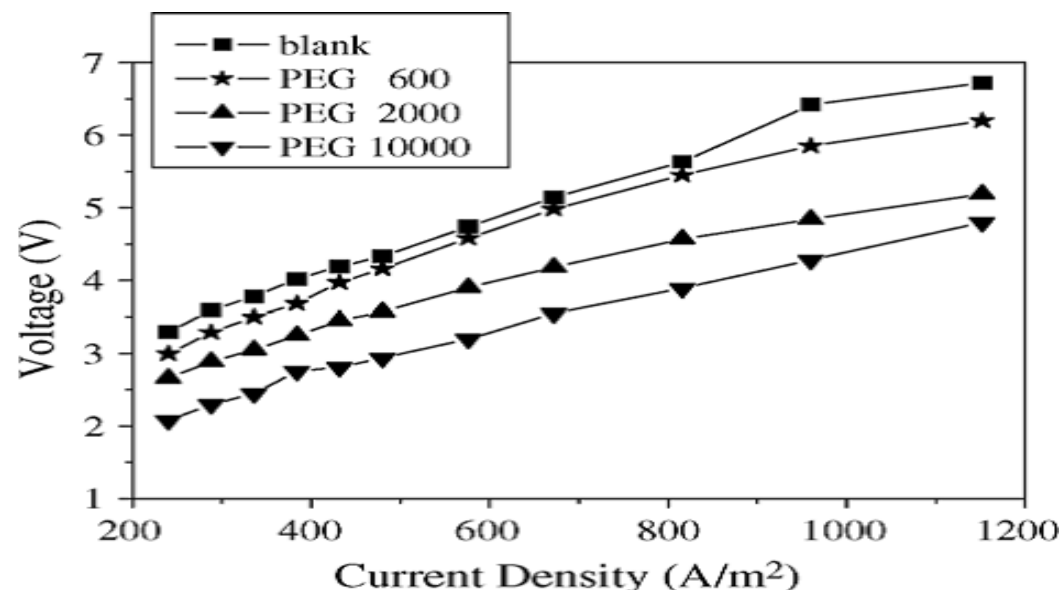

Fig. 3. The I-V curves of bipolar membranes of which the anion exchange membranes have been brushed with 1.0M solutions of different weight of PEGs 
As shown in Fig. 4, PVA performs the catalytic effect only at low adsorptional concentration. Theoretical interpretation has been conducted from the aspects of the strong hydrophilicity and interaction of PEG or PVA with watermolecules. Though both PEGand PVAare hydrophilic, the hydrogen-bonding and polar interactions between PEG andwater molecules are easily formed to increase the solubility of PEG in water, while PVA has a limit in solubility above which it is easily crystallized to give a neutral layer [45].

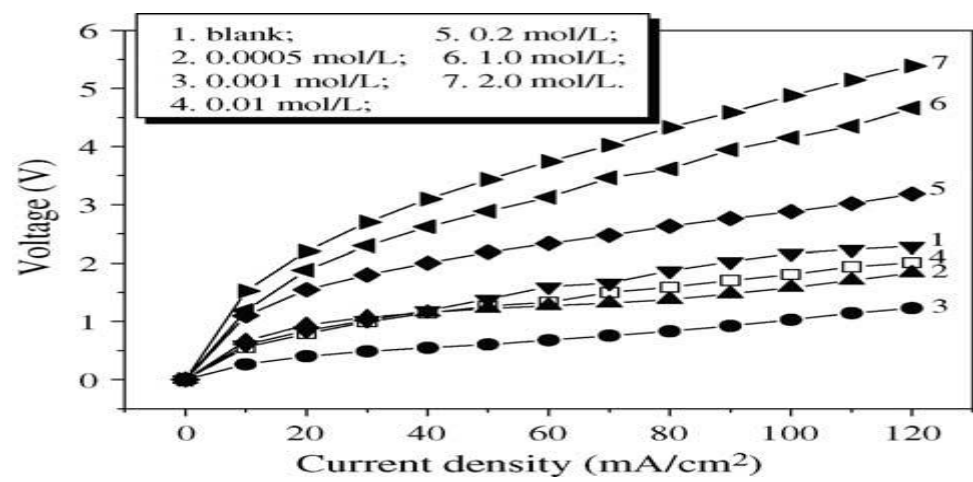

Fig. 4. The I-V curves of bipolar membranes in which anion exchange membranes have been immersed in different concentration PVA solution

As shown in Fig. 5, at a given PAMAMgeneration, taking G2 as an example, voltage decreases with PAMAM concentration at low concentration range due to an increase in catalytic sites from amino groups, and increases with PAMAM concentration at high concentration range due to an increase in steric effect. There exists a transitional concentration for each generation of PAMAM. Below this transitional concentration, PAMAM $\backslash$ has a catalytic function, above it there is a hindrance effect, and at it the voltage across a bipolar membrane reaches a minimum and the catalytic effect is highest. This transitional concentration decreases with an increase in the generation of PAMAMas demonstrated in Fig. 6, in which voltage dependence on concentration for different generations was plotted at a given current density.

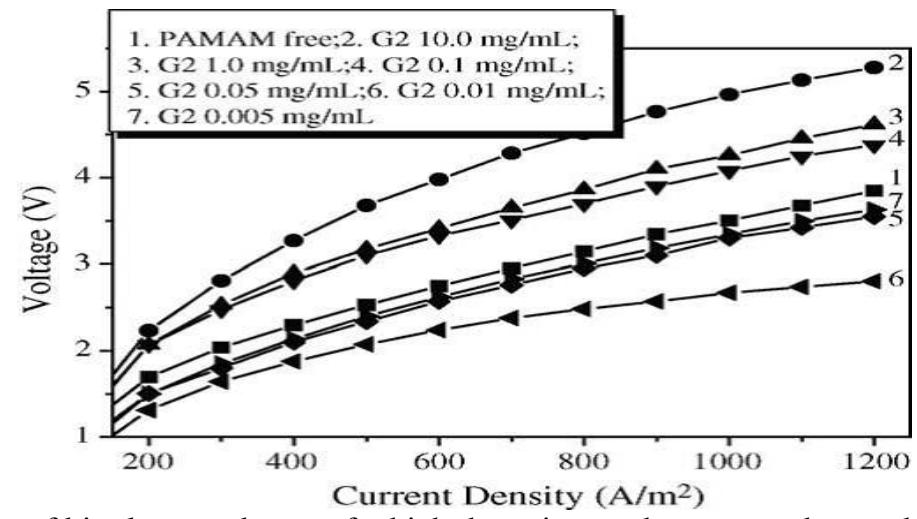

Fig. 5. The I-V curves of bipolar membrane of which the anion exchange membranes have been immersed in different concentration solutions of PAMAM G2.

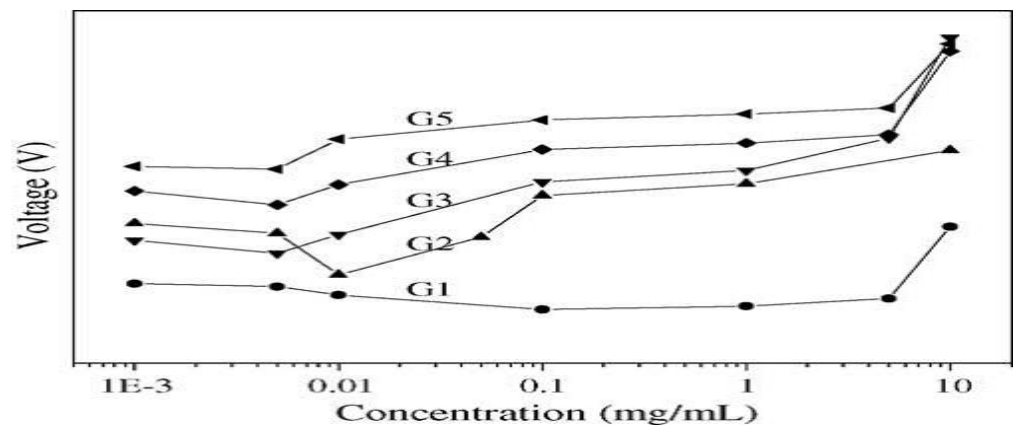

Fig. 6. The relation between the potential drop and the PAMAM concentration at the current density of 1200 $\mathrm{A} / \mathrm{m} 2$.

With proper generation and concentration, PAMAM not only work as a catalysis itself, but also can be used to coordinate the heavy metal ions, such as $\mathrm{Cr} 3+, \mathrm{Fe} 2+$ that have been found to be effective to water dissociation 
[46] but easily lost during the operation. As shown in Fig. 7 [47], the voltages cross the bipolar membranes with both PAMAM and $\mathrm{Cr}$ (III) show the minimum among the investigated bipolar membranes without $\mathrm{Cr}$ (III) and PAMAM or with single Fig. component Cr (III) or PAMAM, indicating a synergism effect in catalyzingwater dissociation. Furthermore, compared with single $\mathrm{Cr}$ (III) as an intermediate layer, PAMAM coordinated Cr (III) receive longer catalytic effect as shown in Fig. 8. Unexpected results were observed for BSA, which contains both carboxylic and amino groups that should enhance the water dissociation according to the chemical reaction model [41]. The experimental results shown in Fig. 9 demonstrated a retardant effect [43]. The reasons are under-lined by the intrinsic properties of BSA molecules: steric effect gives rise to an increase in the thickness of the depletion layer, its amphoteric property weakens the electric field of the junction and hydrophobicity makes the junction less wettable [43]. Much work has been done in searching for better interfacial layer of a BPM. It is shown that it is easy to synthesize a BPM of small piece with tolerated potential, but it is not so easy to prepared a BPM of larger pieces with longer operational stability at severe circumstances, such as high temperature and over limiting current density [25,]. The hybrid bipolar ion exchange membrane will be the next choice.

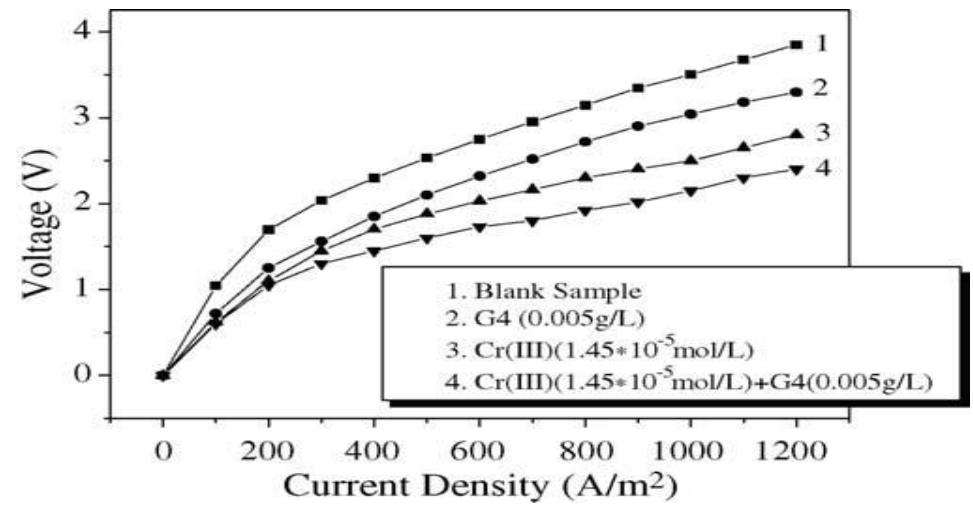

Fig. 7. The $I-V$ curves of bipolar membranes with/without $\mathrm{Cr}$ (III) or PAMAM G4.

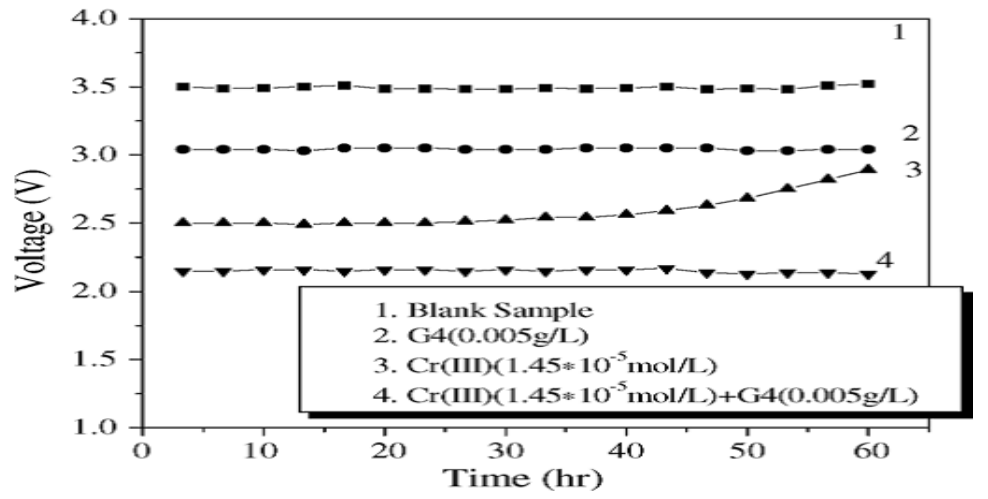

Fig. 8. The $V-t$ curves of bipolar membranes with/without $\mathrm{Cr}$ (III) or PAMAM G4.

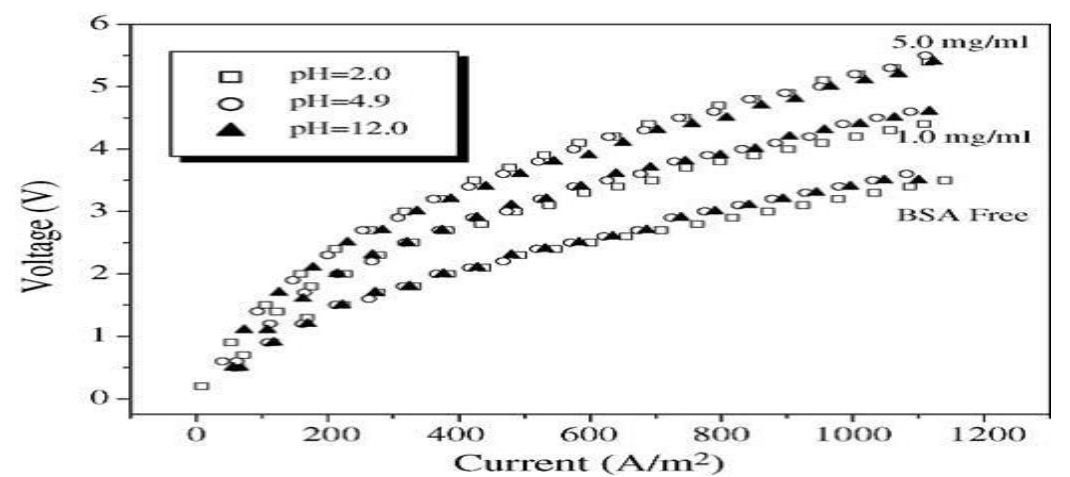

Fig. 9. Effect of BSA in the middle layer on $\mathrm{I}-\mathrm{V}$ curves at different pH values.

\subsection{Amphoteric ion exchange membranes}

Amphoteric ion exchange membranes contain both weak acidic (negative charge) groups and weak basic (positive charge) groups that are randomly distributed within the membrane matrix [48]. The sign of the 
charge groups in these membranes exhibits a $\mathrm{pH}$ response to an external solution. As described earlier, amphoteric ion exchange membranes was first suggested by S" ollner in 1932 together with mosaic membranes. Since then, substantial researchers have been conducted for this kind of membrane. For example, Saito et al. [49] prepared weakly amphoteric polymer membranes from mixed solutions of poly(vinyl alcohol) and succinyl chitosans composed of carboxy and amino groups as the dissociative groups to determine the interactions occurring between the ion exchange groups on the polyampholyte chain and the counter ions. In the same lab, novel weak porous amphoteric charged membranes having cysteine residues were prepared by graftpolymerising poly(ethylene glycol) derivatives (with cysteine residues added to their side chains) onto a porous cellulose acetate membrane [50]. Nonaka et al. prepared homogeneous amphoteric polymer membranes bearing both amino groups and carboxyl groups from 2, 3-epithiopropyl methacrylate (ETMA)butylmethacrylate (BMA)- $N, N$ dimethylaminopropyl acrylamide (DMAPAA)-methacrylic acid (MAc) copolymers. The diffusive permeability of solutes with different charged conditions, and the changes in the membrane potential during the permeation of solutes through the amphoteric polymer membranes was investigated. In addition, Matsuyama et al. studied the permeability of ionic solutes through a polyamphoteric membrane [51]. Ramirez et al. [52] have studied theoretically the effects of $\mathrm{pH}$ on the ion transport through amphoteric polymer membranes composed of weak polyelectrolytes. Takagi and Nakagaki [53] theoretically discusses the permeation of ions through the amphoteric membrane using the advanced amphoteric membrane model shown in Fig. 10 and determines the membrane charge by the dissociation of the amphoteric membrane material as well as the selective adsorption of ions.

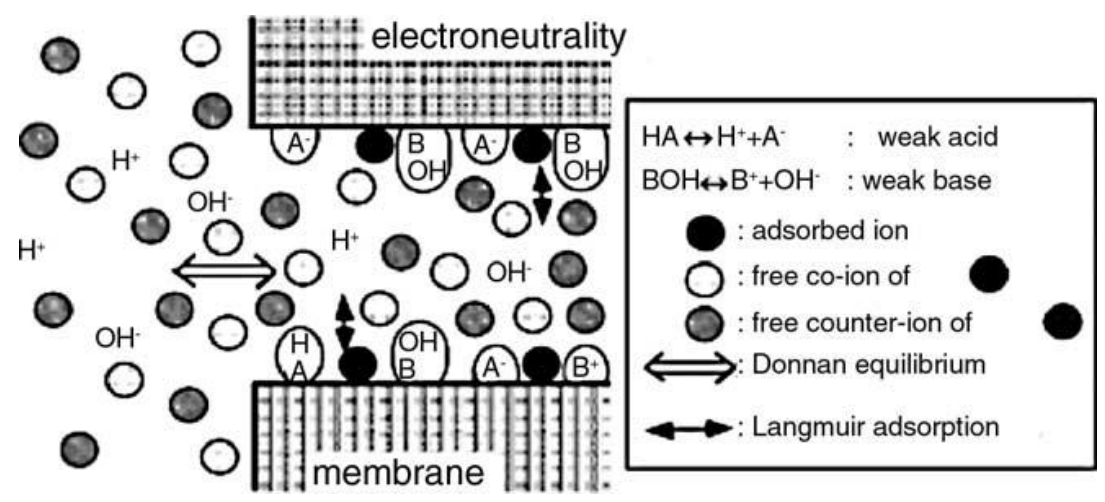

Fig. 10. Advanced amphoteric membrane model, taken from Ref. [53].

\subsection{Mosaic ion exchange membranes}

Differentiating from amphoteric charged membrane with negatively fixed ions and those with positively fixed ions randomly distributed in a neutral polymer matrix, a chargemosaic membrane consists of a set of anion and cation exchange elements arranged in parallel, each element providing continuous pathway from one bathing solution to the other. When a gradient of electrolyte concentration is established across the membrane, anions and cations can flow in parallel through their respective pathways without a violation of macroscopic electroneutrality, resulting in a circulation of current between the individual ion-exchange elements.As a result of current circulation, the charge-mosaic membrane shows negative osmosis and salt permeability much greater than its permeability to non-electrolytes; these effects are not displayed in mono-ion exchange membranes or neutral membranes $[54,55]$.

\subsection{Novel processes based on ion exchange membranes}

The conventional ion exchange membrane-based processes include electrodialysis, diffusional dialysis and Donnan dialysis, which are used today in a large variety of applications from water desalination, waste water treatment to chemical reactors.Detail descriptions of those applications can be found in some books and reviews [56].

Another interesting application of ion exchange membranes is the so-called electrochemical-ion exchange. In this process, an ion exchange membrane is bonded directly on the surface of a metal mesh electrode. By applying a suit-able current, ion-exchange can be enhanced leaving, in some favorable cases, only part per billions of metal ions in the effluent. The regeneration of the resin can be simply attained by reversing the current. Originally developed by A.E.A. Harwell for brackish water desalination, it has afterwards been applied to the removal of ions, such as $\mathrm{Co} 2+, \mathrm{Cs}+, \mathrm{Li}^{+}, \mathrm{Cl}-, \mathrm{SO} 42^{-}$and borates in nuclear waste decontamination, to $\mathrm{Ca} 2+$ and $\mathrm{Mg} 2+$ elimination for water softening, as well as to the recovery of precious metals, etc. [57]. Furthermore, Janssen and Koene showed that ion-exchange-assisted electrodialysis could lead 
to lowresidual heavy metal concentrations (10-2 molm-3), which are one order of magnitude lower than those achievable by direct deposition on bi- or tri-dimensional electrodes [58].

Electrodialysis with a bipolar membrane (BMED) provided an update of conventional electrodialysis (ED). Up to now, substantial efforts have been made to use this new technology for clean production in aqueous system and occasionally in non-aqueous systems. In aqueous system, BMED is not only used in conventional chemical or biochemical production or resources recovery, such as producing inorganic acid/base from the corresponding salts, recovery/produce organic from fermentation broth, etc, but also used in the purification or separation in food industries [59], such as inhabitation of polyphenol oxidase in apple juice, the enzyme responsible for the enzymatic browning of cloudy juice and separation of soybean proteins from other components without denaturing them, in order to produce protein isolates. As an example, Fig.11

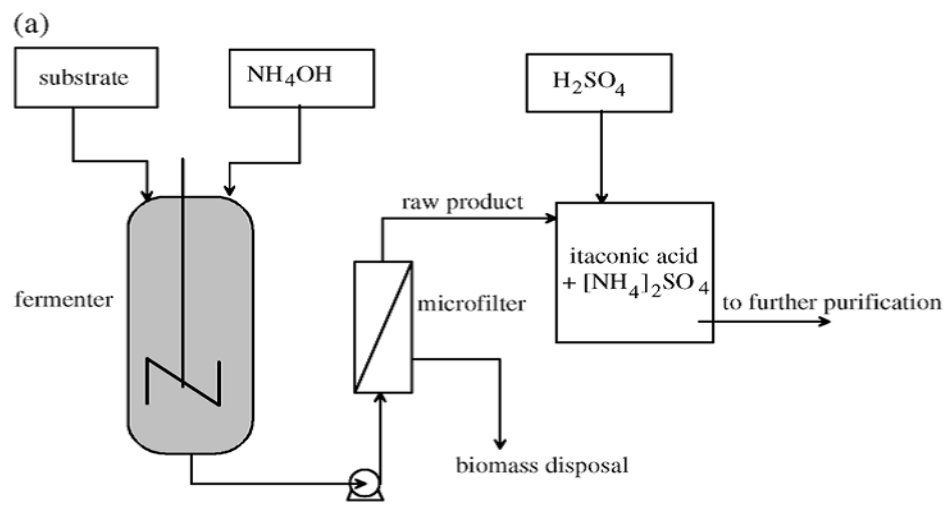

(b)

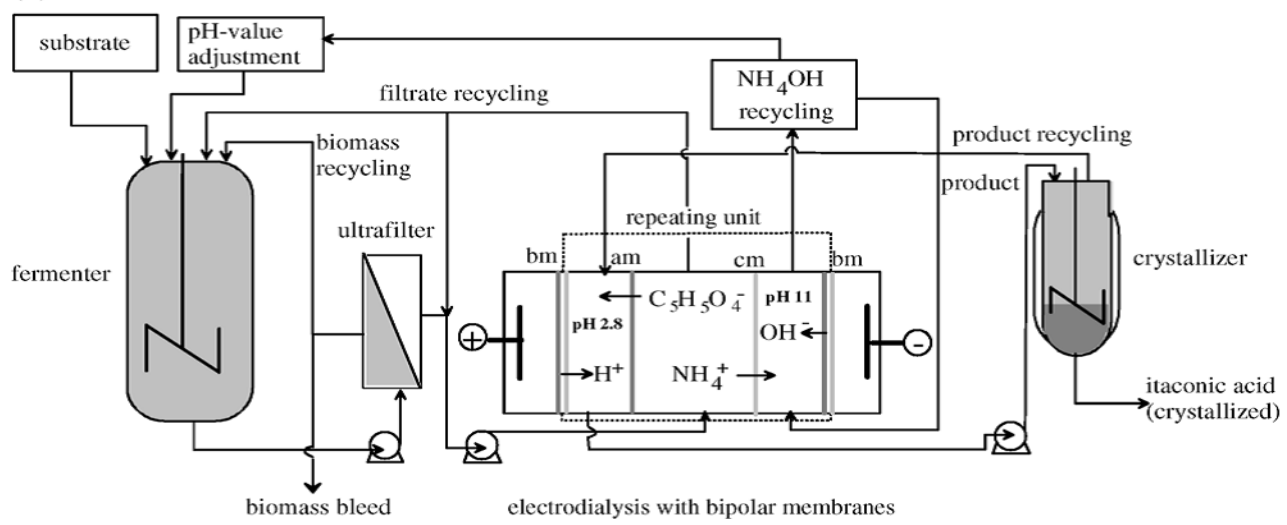

Fig. 11. Simplified flow diagram of the production of it aconic acid (a) by conventional batch fermentation and

(b) continuous fermentation with integrated electrodialysis with bipolar membranes, taken from Ref. [35].

Production of sodium methoxide is an example of BMED used in non-aqueous system [60]. Such application is illustrated in the schematic diagram of Fig. 12, which shows an electrodialysis stack with a bipolar membrane in a repeating unit consisting of two compartments between two electrodes [60]. Water-free methanol and sodium acetate are fed into the cell formed by the bipolar membrane and the cation exchange membrane, which is directed towards the cathode while water-free methanol is fed into the other cell directed towards the anode. Due to an electrical potential gradient between the electrodes, methanol is dissociated in the bipolar Membrane into protons and $\mathrm{CH} 3 \mathrm{O}-$-ions. The proton forms acetic acid with the acetate ions while the $\mathrm{CH} 3 \mathrm{O}^{--}$ ions react with the $\mathrm{Na}$-ions, which migrate from the adjacent sodium acetate containing cell and form $\mathrm{CH} 3 \mathrm{ONa}$. Thus, sodium acetate and methanol are converted to sodium methoxide andacetic acid. The significance of this process is not only for production of sodium methoxide itself but also in turn provides cheap chemicals for various syntheses, such as the Claisen condensation and the intramolecular Dieckmann condensation reactions, which need alkali alkoxides [61]. By means of BMED, such syntheses can be very environmentallybenigned, e.g., production of acetoacetic ester proposed by Sridhar and Feldmann [61]. 


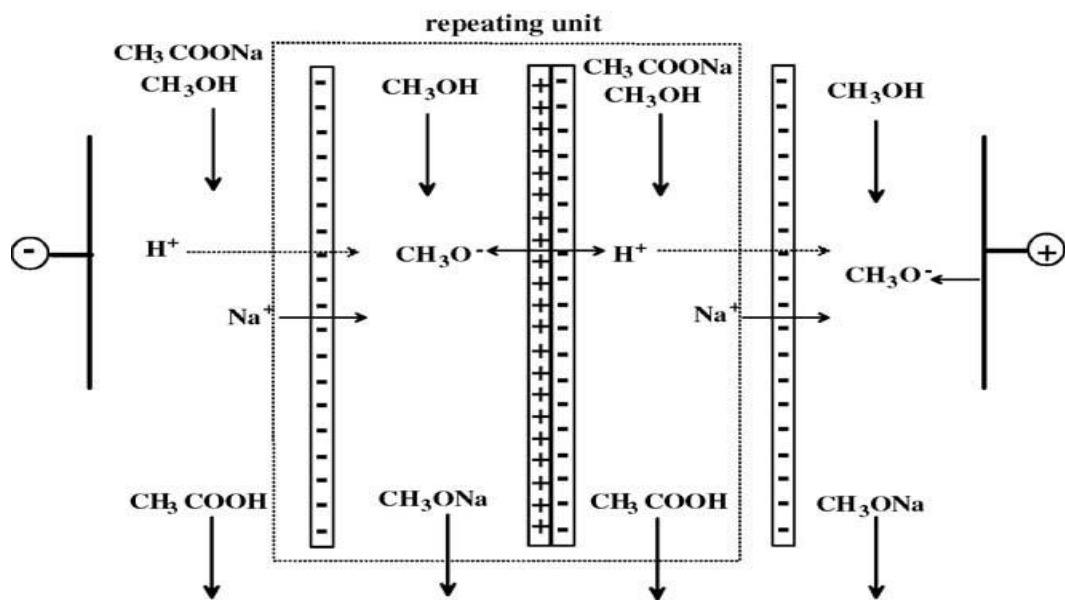

Fig.12.Schematic drawing illustrating the production of sodium methoxidebyelectrodialysis with bipolar membranes from methanol using sodium acetate as electrolyte.

Electro-electrodialysis (EED) is a combination of electrolysis and electrodialysis with ion exchange membranes. Unlike electrodialysis, which simultaneously needs both cation exchange membranes and anion exchange membranes placed in series, EED only needs a single membrane: either anion exchange membrane or cation exchange membrane.As an example, illustrates the process of concentrating HIx solution with EED based on a cation exchange mem-brane [62]. In HIx solution, the electrode reaction was the redox reaction of iodineiodide ions . Consequently, with the help of selective proton permeation through themembrane, it is expected that the aimed "concentration" is possible in the sense that HI molality of catholyte increases while that of anolyte decreases [62]. Another example for EED with an anion exchange membrane is for the electro-oxidation of cerium (III) to cerium (IV) and simultaneous deposition of copper powder on cathode [63]. As shown in Fig. 13, anolyte is cerium (III) sulfate solution and catholyte is copper sulfate solution. With the passage of an electrical current, cerium (III) oxidizes to cerium (IV) at the anode with the reaction:

$\mathrm{Ce} 2(\mathrm{SO} 4) 3+\mathrm{SO} 42-\rightarrow \mathrm{Ce}(\mathrm{SO} 4) 2+2 \mathrm{e}$

And simultaneously copper deposits on the cathode with the reaction:

$\mathrm{CuSO} 4+2 \mathrm{e} \rightarrow \mathrm{Cu}+\mathrm{SO} 4$ $2-(6)$

The function of the anion exchange membrane is to let the SO4 2- transport from cathode chamber to anode chamber to balance charges. Apart from these examples, EED is a potential technology for electrochemical reaction in many industries, especially in hydrometallurgy industry [63]. The most important potential largescale application of ion exchange membrane is their use as separators in fuel cells and batteries. Though Nafion series membranes have been specially designed for this purpose, its high cost and high hydrogen or methanol leaching increase the instability of the related industries. Recently, a bipolar membrane is used as protonconductive polymer electrolyte in the methanol direct-conversion fuel cell [64]. The principle is shown in Fig. 14.

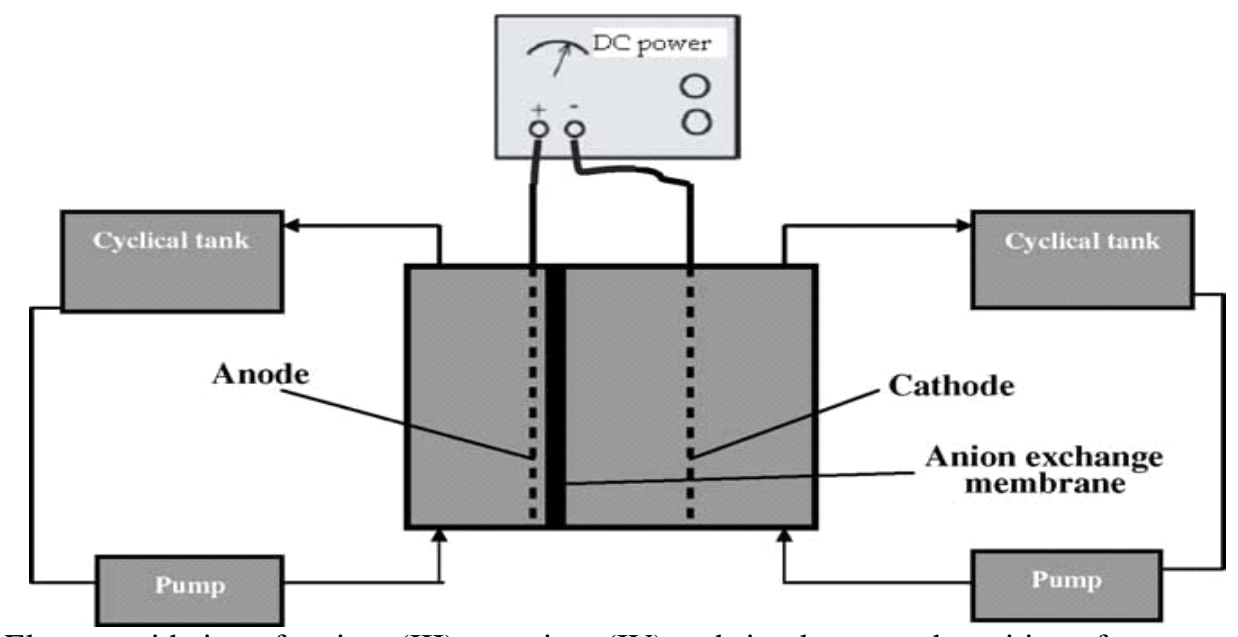

Fig. 13. Electro-oxidation of cerium (III) to cerium (IV) and simultaneous deposition of copper powder on cathode by EED with an anion exchange membrane. 


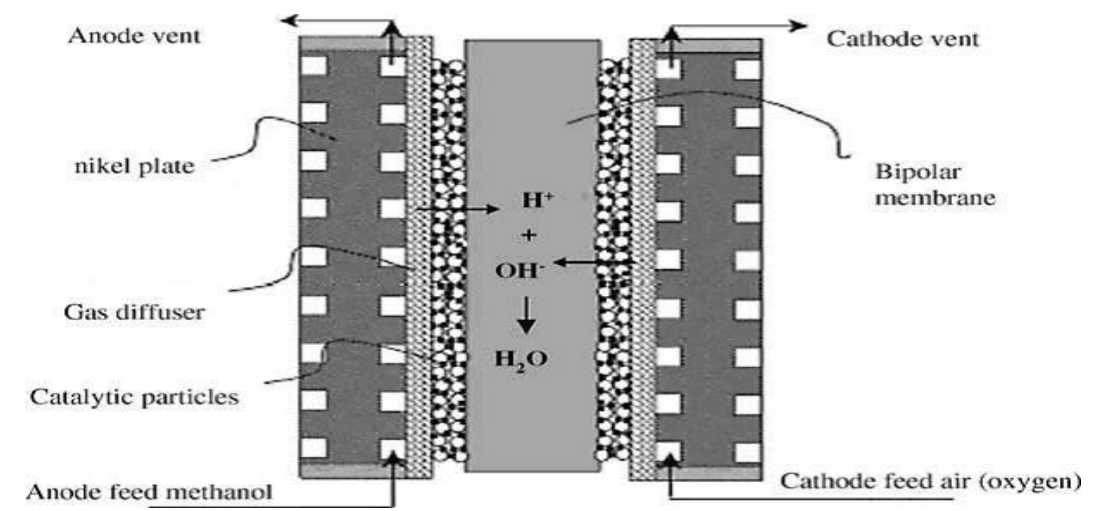

Fig.14. Schematic representation of methanol direct-conversion fuel cell with a bipolar membrane as polymer electrolyte, adapted from Ref. [32].

Another interesting application, which is presently studied, is the integration of ion exchange membrane in the so-called membrane reactors. Fig. 15 shows such integration applied for the treatment of drinking water with high nitrate concentration $[65,66]$. The ground water contaminated by nitrate resulting from various agricultural and farm activities were first treated by electodialysis and concentrated brines were then treated by a membrane bioreactor (MBR). The results showed that the MBR allowed efficient denitrification of ED concentrates despite the drastic conditions of nitrate concentration, $\mathrm{pH}$ and salinity. The nitrate concentration of ED dilutes remained below the acceptable value $50 \mathrm{mg} / \mathrm{l}$ ) and could be drinkable [65, 66]. In addition, in many chemical and biochemical reactions, the reaction products or the reaction by-products inhibit the reaction when a certain concentration is exceeded. This often limits the achievable product concentration and requires additional separation and concentration steps. A continuous removal of the reaction inhibiting components often makes a continuous more economic production possible.

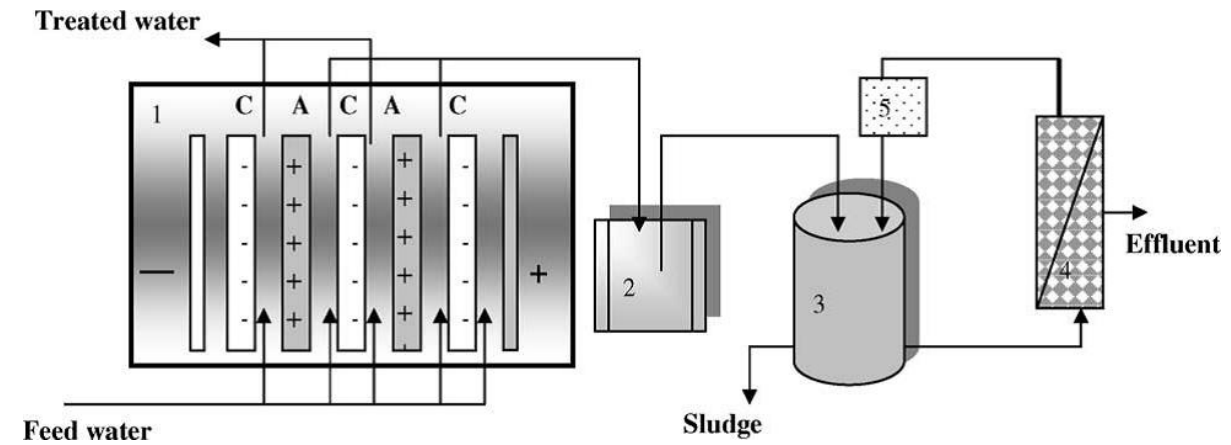

Fig. 15. Schematic diagram in denitrification of drinking water by the association of an electrodialysis (ED) process and a membrane bioreactor (MBR), adapted from Ref. [66]. 1, ED stack; 2, MBR feed tank; 3, fermentor; 4, ultra-filtration module; 5, temperature regulator; $\mathrm{C}$, cation exchange membrane; $\mathrm{A}$, anion exchange membrane.

\section{Conclusions}

From this survey, ion exchange membrane technologies clearly appear to be versatile and capable of solving quite different problems. The author feels that most of the future developments in the area will come from those developers or users that will look at these technologies as tools to cope with their specific treatment requirements. But it should be emphasized that, for any purpose, preparation of ion exchange membranes or materials is the most crucial. In the last decade, the development of new membrane materials has gained the advantage of an interdisciplinary approach integrating recent advances in the field of material science. A number of examples developed on ion exchange membrane preparation in this paper demonstrate the interest of using innovative methods for material processing. The sol-gel process is certainly the most appropriate way to produce purely inorganic or hybrid ion exchange membranes with various reactivity or permselectivity, and phase inversion is the key steps for organic ion exchange membrane. But what should be emphasized here, as a result of these intensified research efforts, much has been accomplished in the past decade, and we are finding the potential applications for a given membrane. To satisfy with a specific requirement, one had to choose a "proper" membrane from the "sea of membranes", optimize the operational condition and then design the process. Such application status is limited by the current researches status; the relation between electromembrane function and structure, the controlled formation of electro-membranes and the properties evolution of 
electro-membranes with time leave to be quantitatively determined at this time. Obviously, in the future, it is necessary to discard this old mode and establish a new one for synthesis and application of ion exchange membranes.

The evolution of electro-membranes properties and microstructure with elapse time should be decided. Apart from the preparation of ion exchange membranes, the technical and commercial relevance of the ion exchange membrane-based processes should also be considered. As analyzed by Strathmann in his recent work [35], some of the applications can be considered as state-of-the-art technology, such as the applications using conventional electrodialysis, production of pure water using continuous electrodeionization and some specific applications using bipolar membranes, such as producing organic acid from the fermentation broth or recovering HF and HNO3 from a waste stream generated by neutralization of a steel pickling bath; while other applications are still in the pilot plant or even laboratory stage, such as the production of acids and bases by electrodialysis with bipolar membranes. Often ion exchange membrane separation processes are in competition with other mass separation techniques and their application is determined by economic considerations. In some applications, ion exchange membrane processes provide higher quality products or are more environmentally friendly and will therefore be used in spite of a cost disadvantage. Also, increasing costs of raw materials and environmental awareness have increased the application of ion exchange membrane separation processes especially in highly industrialized and densely populated countries.

Actually, the development of electro-membrane system has gained the advantage of an interdisciplinary approach integrating recent advances in the every field of science and technology, and therefore, technologists and researchers should give exceptional considerations to interdisciplinary knowledge, such as material, inorganic, polymer science and technology, mathematics as well as engineering to solve some multifold problems, such as apparatus design and operating conditions optimum in electro-membrane processes.

\section{References}

[1] Nickel in Drinking-water Background document for development of WHO Guidelines for Drinking-water Quality. WHO/SDE/WSH/05.08/55.

[2] Healthy Drinking Waters for Rhode Islanders. SAFE AND HEALTHY LIVES IN SAFE AND HEALTHY COMMUNITIES.

[3] Tongwen $\mathrm{Xu}$, ReviewIon exchange membranes: State of their development and perspective; Available online 15 August 2005

[4] H. Herman, R.C.T. Slade, J.R. Varcoe, The radiationgrafting of vinylbenzyl chloride onto poly (hexafluoropropylenecotetrafluoroethylene) films with subsequent conversion to alkalineanion exchange membranes: optimisation of the experimental conditions and characterization, J. Membr. Sci. 218 (2003) 147.

[5] W. Lee, K. Saito, S. Furusaki, T. Sugo, K. Makuuchi, Design of urea-permeable anion exchange membrane by radiation-induced graft-polymerization, J. Membr. Sci. 81 (1993) 295.

[6] G. Kickelbick, Concepts for the incorporation of inorganic building blocks into organic polymers on a nanoscale, Prog. Polym. Sci. 28 (2003) 83.

[7] A. Okada, A. Usuki, The chemistry of polymer-clay hybrids, Mater. Sci. Eng. C 3 (1995) 109.

[8] J.W. Gilman, Flammability and thermal stability studies of polymer layered-silicate (clay) nanocomposites, Appl. Clay Sci. 15 (1999) 31.

[9] M. Zanetti, S. Lomakin, G. Camino, Polymer layered silicate nanocomposites, Macromol. Mater. Eng. 279 (2000) 1.

[10] S.P. Armes, Electrically conducting polymer colloids, Polym. News 20 (1995) 233.

[11] T. Sakata, K. Hashimoto, M. Hiramoto, New aspects of electron transfer on semiconductor surface: dye-sensitization system, J. Phys. Chem. 94 (1990) 3040.

[12] J. Takada, H. Awaji, M. Koshioka, A. Nakajima, W.A. Nevin, Organic-inorganic multilayers: a new concept of optoelectronic material, Appl. Phys. Lett. 61 (1992) 2184

[13] D.B. Mitzi, Thin-film deposition of organic-inorganic hybrid materials,Chem. Mater. 13 (2001) 3283.

[14] B. Bauer, F.J. Gerner, H. Strathmann, Development of bipolar membranes, Desalination 68 (1988) 279.

[15] T.W. Xu, Development of a bipolar membrane-based process, Desalination 140 (2001) 247.

[16] H. Mueller, H. Puetter, Production of bipolar membrane, U.S. Patent 4,670,125 (1987).

[17] P. Francesco, S.L. Rosignano, Method for making a bipolar membrane, U.S. Patent 5,849,167 (1998).

[18] R.G. Simons, R. Bay, High performance bipolar membranes, U.S. Patent 5,227,040 (1993).

[19] L.T.C. Lee, G.J. Dege, K.J. Liu, High performance, quality controlled bipolar membrane, U.S. Patent 4,057,481 (1997).

[20] K. Nagsubramanian, F.P. Chlanda, K.J. Liu, Use of bipolar membrane for generation of acid and base-an engineering and economic analysis, J. Membr. Sci. 2 (1977) 109.

[21] S. Thate, G. Eigenberger, H.J. Rapp, Introduction, in: A.J.B. Kemperman (Ed.), Handbook on Bipolar membrane Technology, Twente University Press, Enschede, 2000, pp. 9-16 (Chapter 1).

[22] K.N. Mani, Electrodialysis water-splitting technology, J. Membr. Sci. 58 (1991) 117

[23] H. Strathmann, G.H. Koops, Process economics of the electrodialytic water dissociation for the production of acid and base, in: A.J.B. Kemperman (Ed.), Handbook on Bipolar Membrane Technology, Twente University Press, Enschede, 2000 , pp. $193-218$.

[24] V. Frilette, Preparation and characterization of bipolar ion exchange membranes, J. Phys. Chem. 60 (1956) 435.

[25] F. Wilhelm, N.V.D. Vegt, M. Wessling, H. Strathmann, Bipolar membrane preparation, in: A.J.B. Kemperman (Ed.), Handbook Bipolar Membrane Technology, Twente University Press, Enschede, 2000, pp. 79-108.

[26] J.H. Hao, C.X. Chen, L. Li, L.X. Yu, W.J. Jiang, Preparation of bipolar membranes (I), J. Appl. Polym. Sci. 80 (2001) 1658.

[27] R.Q. Fu, T.W. Xu, W.H. Yang, Z.X. Pan, Preparation of a monosheet bipolar membrane by simultaneous irradiation grafting polymerization of acrylic acid and chloromethylstyrene, J. Appl. Polym. Sci. 90 (2003) 572.

[28] A. Jendrychowska-Bonamour, Semipermeable membranes synthesized by grafting poly(tetrafluoroethylene) films. Synthesis and study of properties. II. Anionic and cationic mixed membranes, J. Chim. Phys. Phys. Chim. Biol. 70 (1973) 16.

[29] Z. Xu, H. Gao, M. Qian, Y. Yu, G. Wan, B. Chen, Preparation of bipolar membranes via radiation peroxidation grafting, Radiat. Phys. Chem. 42 (1993) 963. 
[30] E.A. Hegazy, H. Kamal, N. Maziad, A. Dessouki, Membranes prepared by radiation grafting of binary monomers for adsorption of heavy metals from industrial wastes, Nucl. Instrum. Meth. Phys. Res. B 151 (1999) 386.

[31] R. El Moussaoui, H. Hurwitz, Single-film membrane-process for obtaining it and use thereof, U.S. Patent 5,840,192 (1998),

[32] B. Gupta, A. Chapiro, Preparation of ion exchange membranes by grafting acrylic acid into pre-irradiated polymer films. 1. Grafting into polyethylene, Eur. Polym. J. 25 (1989) 1137.

[33] N.V. Sheldeshov, N.P. Gnusin, V.I. Zabolotskii, N.D. Pis'menskaya, Chronopotentiometric study of electrolyte transport in commercial bipolar membranes, Soviet Electrochem. 22 (1987) 742.

[34] R. Simons, Strong electric field effects on proton transfer between membrane-bound amines and water, Nature 280 (1979) 824.

[35] R. Simons, Electric field effects on proton transfer between ionizable groups and water in ion exchange membranes, Electrochim. Acta 29 (1984) 151.

[36] R. Simons, Water splitting in ion exchange membranes, Electrochim. Acta 30 (1985) 275.

[37] F. Hanada, K. Hirayama, N. Ohmura, S. Tanaka, Bipolar membrane and method for its production, U.S. Patent 5,221,455 (1993).

[38] R. Simons, A novel method for preparing bipolar membranes, Electrochim. Acta 31 (1986) 1175.

[39] R. Simons, Preparation of a high performance bipolar membrane, J. Membr. Sci. 78 (1993) 13

[40] K. Umemura, T. Naganuma, H. Miyake, Bipolar membrane, U.S. Patent 5,401,408 (1995).

[41] R. Simons, The origin and elimination of water splitting in ion exchange membranes during water demineralisation by electrodialysis, Desaliantion 28 (1979) 41.

[42] R.Q. Fu, T.W. Xu, G. Wang, W.H. Yang, Z.X. Pan, Fundamental studies on the intermediate layer of a bipolar membrane. Part I. PEG-catalytic water splitting in the interface of a bipolar membrane, J. Colloid Interface Sci. 263 (2003) 386.

[43] R.Q. Fu, T.W. Xu, G. Wang, W.H. Yang, Z.X. Pan, Fundamental studies on the intermediate layer of a bipolar membrane. Part II. Effect of bovine serum albumin (BSA) on water dissociation atthe interface of a bipolar membrane, J. Colloid Interface Sci. 278 (2004) 318.

[44] R.Q. Fu, T.W. Xu, Y.Y. Cheng, W.H. Yang, Z.X. Pan, Fundamental studies on the intermediate layer of a bipolar membrane. Part III. Effect of starburst dendrimer PAMAM on water dissociation at the interface of a bipolar membrane, J. Membr. Sci. 240 (2004) 141.

[45] R.Q. Fu, T.W. Xu, Fundamental studies on the intermediate layer of a bipolar membrane. Part IV. Effect of polyvinyl alcohol (PVA) on water dissociation at the interface of a bipolar membrane, J. Colloid Interface Sci. 285 (2005) 28.

[46] H. Hurwitz, R.E. Moussaoui, Bipolar membrane and method for fabricating such bipolar membrane, WO Patent 96/01286 (1996).

[47] R.Q. Fu, The selection of the catalytic layer of a multi-layer bipolarmembrane and the investigation of water dissociation therein, Ph.D. Dissertation, University of Science and Technology of China, 2005.

[48] T. Jimbo, A. Tanioka, N. Minoura, Fourier transform infrared spectroscopic study of flat surfaces of amphoteric-charged poly(acrylonitrile) membranes: attenuated total reflection mode,Langmuir 15 (1999) 1829.

[49] K. Saito, S. Ishizuka, M. Higa, A. Tanioka, Polyamphoteric membrane study. 2. Piezodialysis in weakly amphoteric polymer membranes, Polymer 37 (1996) 2493.

[50] H. Matsumoto, Y. Koyama, A. Tanioka, Preparation and characterization of novel weak amphoteric charged membrane containing cysteine residues, J. Colloid Interface Sci. 239 (2001) 467.

[51] H. Matsuyama, T. Tamura, Y. Kitamura, Permeability of ionic solutes in a polyamphoteric membrane, Sep. Purif. Technol. 16 (1999) 181.

[52] P. Ramirez, A. Alcaraz, S. Mafe, Effects of pH on ion transport in weak amphoteric membranes, J. Electroanal. Chem. 436 (1997) 119.

[53] R. Takagi, M. Nakagaki, Ionic dialysis through amphoteric membranes, Sep. Purif. Technol. 32 (2003) 65.

[54] J.N. Wein, B.J. Bunow, S.R. Caplan, Theoretical properties of charge-mosaic membranes. 1. Models, Desalination 11 (1972) 341

[55] J.N. Weinstein, B.W. Misra, D. Kalif, S.R. Caplan, Transport properties of charge-mosaic membranes. II. Experimental studies, Desalination 12 (1973) 1.

[56] B.L. He, T.W. Xu, X.H. Li, Manufacture and applications of ion exchange membranes in China, Ion Exch. Adsorpt. 14 (1998) 86 (in Chinese).

[57] F. Walsh, G. Mills, Chem. Technol. Eur. 1 (1994) 13

[58] L.J.J. Janssen, L. Koene, The role of electrochemistry and electrochemical technology in environmental protection, Chem. Eng. J. 85 (2002) 137.

[59] S.J. Lue, B.H. Chiang, Deacidification of passion fruit juice by ultrafiltration and ion-exchange processes, Int. J. Food Sci. Technol. 24 (1989) 395.

[60] S. Sridhar, Electrodialysis in a non-aqueous medium: production of sodium methoxide, J. Membr. Sci. 113 (1996) 73.

[61] S. Sridhar, C. Feldmann, Electrodialysis in a non-aqueous medium: a clean process for the production of acetoacetic ester, J. Membr. Sci. 124 (1997) 175.

[62] Arifal, G.J. Hwang, K. Onuki, Electro-electrodialysis of hydriodic acid using the cation exchange membrane crosslinked by accelerated electron radiation, J. Membr. Sci. 210 (2002) 39.

[63] Q.X. Zhang, Sciences and Technologies in Hydrometallurgy Separations, Science Press of China, Beijing, 2004, pp. $276-307$.

[64] H.Y. Ding, Direct methanol fuel cell with bipolar membranes as electrolytes, Private communication.

[65] C. Wisniewski, F. Persinb, T. Cherif, R. Sandeauxb, A. Grasmick, C. Gavachb, F. Lutin, Use of a membrane bioreactor for denitrification of brine from an electrodialysis process, Desalination 149 (2002) 331.

[66] C. Wisniewski, F. Persin, T. Cherif, R. Sandeaux, A. Grasmick, C. Gavach, Denitrification of drinking water by the association of an electrodialysis process and a membrane bioreactor: feasibility and application, Desalination 139 (2001) 199. 